\title{
Female Headed Households and Poverty in Rural Ethiopia
}

\author{
Alemi Negassa Muleta $^{1^{\star}}$ and Dereje Fekadu Deressa ${ }^{2}$ \\ ${ }^{1}$ Ethiopian Commodity Exchange, P.O. Box: 17341, Nekemte, Ethiopia \\ ${ }^{2}$ Department of Economics, College of Business and Economics, Wollega University, P.O. Box: 395, \\ Nekemete, Ethiopia
}

\begin{tabular}{|c|c|}
\hline Abstract & Article Information \\
\hline \multirow{11}{*}{$\begin{array}{l}\text { The study has tried to examine the extent of poverty of female-headed households by the } \\
\text { way of making comparisons with their male counterparts in rural Ethiopia. It further looks } \\
\text { through the determinants of poverty in female headed households. It is based on the } \\
\text { Ethiopian Rural Household Survey from 1999-2009. Using the Foster, Greer and } \\
\text { Thorbecke (FGT) poverty indices, the descriptive analysis of poverty indices revealed that } \\
\text { female-headed households are poorer than male-headed households. To further } \\
\text { investigate the determinants of female headed household's Logit model was estimated. } \\
\text { Based on the estimation result variables such as educational attainment of the head, } \\
\text { household size, total livestock owned as measured in total livestock unit and land holding } \\
\text { are found to be the key determinants of poverty for female headed households. Gender- } \\
\text { sensitive poverty alleviation policies that enhance endowments such as those that increase } \\
\text { livestock ownership, land productivity, education level, and ability to control fertility should } \\
\text { be the key ingredients of a poverty reduction strategy in rural Ethiopia. Hence, there is an } \\
\text { evidence to suggest that poverty alleviation programs should use female headed } \\
\text { households as proxy variables for targeting the poor. }\end{array}$} & $\begin{array}{l}\text { Article History: } \\
\text { Received : 03- }\end{array}$ \\
\hline & : 19-03-2014 \\
\hline & Accepted : 21-03-2014 \\
\hline & $\begin{array}{l}\text { Keywords: } \\
\text { Female-headed households }\end{array}$ \\
\hline & Poverty \\
\hline & Rural Ethiopia \\
\hline & Greer and Thor \\
\hline & \\
\hline & \\
\hline & \\
\hline & \\
\hline
\end{tabular}

\section{INTRODUCTION}

Gender discrimination resulting in greater poverty among women is widespread throughout the developing world. However, the incidence of women poverty, as well as its depth and their vulnerability, is particularly marked in Sub-Saharan African countries of the tropical belt, albeit with significant rural-urban differences (Hazel, 2010).

While concerted efforts are being made internationally for alleviating poverty, there is a growing realization that poverty is increasingly taking on a feminine form, meaning that globally women are bearing a disproportionately higher and growing burden of poverty (Khalid and Akhtar, 2011). This assertion as articulated by the concept of feminization of poverty has been under much debate and discussion in development policy circles in recent years.

Over years the government of Ethiopia Has made efforts to empower women in decision-making processes in order to facilitate the attainment of the country's sustainable development goals. The establishment of the Women's Affairs Office in the country and the formulation of a national policy on women, which entitles and ensures women's right to property, employment and pension illustrate the commitment of the government to gender empowerment (UN, 2012). Nevertheless, gender empowerment in the country is facing a number major constraints, including the low level of consciousness by the population about the roles played by women in the development of the country; the deep-rooted cultural beliefs and traditional practices that prevent women from fully participating in the development process of the country; lack of appropriate technology to reduce the workload of women at the household level; and the shortage of qualified female development agents to help motivate and empower rural women (Meron, 2009).

Although poverty in the country is not limited to female-headed households, the extent of the problem to this group compared to their male counterparts, suggest that these households should be given due attention in the effort of poverty alleviation (Meron, 2009). To that extent, studies that test the validity of the concern that $\mathrm{FHHs}$ are poorer than $\mathrm{MHH}$, assess their vulnerability to poverty and also identify the major determinants for the causes of the problem would have relevant policy implication for the efforts of poverty reduction programs. Hence, the theme of this study is to maximize the understanding of the linkage between female-headed household poverty and its determinants in rural Ethiopia using the 1999-2009 ERHS panel data in a probabilistic modeling framework.

The study gives an insight to the nexus between gender and government rural development policy as perceived by rural community in Ethiopia. The study identifies the poor $\mathrm{FHHs}$ along with their characteristics. The research also applies comparison of male and female headed households to identify sources of vulnerability, 


\section{Alemi Negassa and Dereje Fekadu}

resource endowments, support institutions, priority livelihood strategies and possible outcomes and variations in households. Through identifying some of the key micro level binding constraints to poverty reduction, the study also provides a critical insight for policy makers to trace out major causes of poverty in FHHs.

Female headed households in developing countries deserve special attention since they are typically disadvantaged regarding the access to land, labor, credit and insurance markets, discriminated against by cultural norms and suffering from, among others, high dependency burdens, economic immobility and the "double day burden" of their heads (Khalid and Akhtar, 2011).

More than one third of the Ethiopian's people live in poverty, and gender-bias against women is deeply ingrained in the society placing female-headed households at potentially a greater risk of poverty. "Affirmative efforts" were made, both in the enforcement of new legislation and to address gender-specific disadvantages in effective and concrete ways. However formal reforms are not sufficient to lessen poverty among Ethiopia women. It is important to note that unless the differences between $\mathrm{MHH}$ and $\mathrm{FHHs}$ is identified and the impact of different factors on men on the lives of women and men are analyzed, understood and captured fully by all poverty interventions, it will be very difficult to tackle poverty in Ethiopia (MOFED, 2012).

In Ethiopia FHHs are more illiterate and unemployed with most of them concentrating in informal sector activities, by that they are female heads has an impact on the welfare or poverty status of the households through affecting their level of education and employment status (Meron, 2009). This justifies the need to pay attention to gender dimensions in rural livelihoods as an entry point to address gender differentiated opportunities in development towards alleviating poverty. Any policy to reduce overall poverty in Ethiopian must address the female face of Ethiopian poverty. To address this challenge, one needs to analyze the influence on Ethiopian women poverty of a number of factors. This requires a deep look at the factors responsible for Female headed household's poverty. The objectives of the present study are to measure the level of poverty on female headed households in rural Ethiopia and to identify the determinants of poverty of FHHs in rural Ethiopia.

\section{MATERIALS AND METHODS}

A quantitative dataset from the Ethiopian Rural Household Survey (ERHS) was used. The Ethiopian Rural Household Survey data was collected by the Department of Economics, Addis Ababa University, Oxford University and International Food Policy Research Institute. The collected dataset was having seven rounds they are round one (1994a), round two (1994b), round three (1995), round four (1997), round five (1999), round six (2004), and round seven (2009).

The ERHS consists of core modules that provide detailed information on household demographics, assets, and agricultural income. It also provides information on ownership of land and livestock and crop production and it includes modules that provide information on consumption, health, and women's activities. However, interpretation of results has to take into account that the
Sci. Technol. Arts Res. J., Jan-March 2014, 3(1): 152-155

data is not (and was not intended to be) nationally representative since pastoralist and urban areas are not included (Bilisuma, 2010)

Binary response models (e.g. probit, logit) are used where poverty is considered as a "yes" or "no" decision. A Logit model is adopted in order to model factors that determine the probability whether a household is poor or not, i.e., the incidence of poverty. Between logit and probit, which model is preferable? In most applications the models are quite similar, the main difference being that the logistic distribution has slightly fatter tails. That is to say, the conditional probability $P_{i}$ approaches zero or one at a slower rate in logit than in probit. Therefore, there is no compelling reason to choose one over the other. In practice many researchers choose the logit model because of its comparative mathematical simplicity (Gujarati, 1995). Hence the logit model is used for this study. Here the dependent variable is thus dichotomous, indicating whether a $\mathrm{FHH}$ household is poor or not relative to the poverty line. The model is given as:

$$
Y_{i t}^{*}=\beta X_{i t}^{\prime}+\varepsilon_{i t}
$$

Where $Y_{i}{ }^{*}$ is the underlying response variable in which $Y i=1$ if poor, $Y i=0$ if non-poor, and $X i$ is a set of explanatory variables, and $U_{i}$ is the residual. And the coefficients of the estimated model give the factors that more likely make households poor.

Here poor or non-poor are defined according to the following poor categories: poor; PCAE (Per capita Adult Equivalent Expenditure) below 3781. Non-poor; PCAE expenditure greater or equal to $\mathrm{Br}$. 3781. Inflating of the poverty lines based on CSA data on price indexes is made for 1999, 2004 and 2009. Hence, the survey data is measured in terms of the price of $2010 / 11$ to use the poverty line of 3781 . In order to measure the extent of poverty, we need to develop a poverty measure that can summarize the magnitude of poverty. In many studies, FGT (Foster, Greer, and Thorbecke) measure of poverty developed by Foster et al., 1984 has been found manageable in presenting information on the poor; hence will be used in this study too. This measure summarizes the level, depth and severity (incidence, inequality and intensity respectively) of poverty.

According to the FGT formula at the family/ household level, poverty is measured according to the following expression:

$$
\begin{aligned}
& P\left(c_{h t}\right)= {\left[\frac{z-c_{h t}}{z}\right]_{\text {if }}^{\alpha} C t \leq z } \\
& 0 \text { otherwise }
\end{aligned}
$$

Here $z$ is the poverty line. In this study the national poverty line of the country will be used for analysis. Going by the permanent income hypothesis, welfare indicators based on consumption are preferred over those based on income. Consumption (Ct) to measure poverty is used, for consumption is generally regarded as the best indicator of welfare in rural Ethiopia, because most people in the rural areas consume from their produce and do not earn regular off-farm income (Fredu, 2008). 


\section{RESULTS AND DISCUSSION}

The study focused on the conditions of poverty and the related determinant factors of female headed households in rural Ethiopia. The data is analyzed by both descriptive statistics and econometric analysis techniques. The descriptive methods are employed to explain the level and extent of poverty for female headed households among the different demographic and socio economic variables in the study area. To have deep insights whether there is feminization of poverty or not a comparative view of the status of $\mathrm{FHHs}$ is made with that of $\mathrm{MHHs}$. The econometric analyses enlighten the determining factors for poverty of female headed households hence give empirical evidences for the basic research questions of the study. The ERHS has covered 1383, 1350 and 1357 households in 1999, 2004 and 2009 respectively in rural areas of Ethiopia. From the sampled households femaleheaded households comprise about $23.5 \%, 21.7 \%$ and $38.98 \%$ of the household heads in 1999, 2004 and 2009 respectively. The number of male headed households is quite larger than the ones headed by females but the numbers of female headed households are increasing (Table 1).

Table 1: Gender of the household head by year.

\begin{tabular}{|c|c|c|c|c|c|}
\hline \multirow{3}{*}{ Year } & \multicolumn{4}{|c|}{ Gender of the head } & \multirow{3}{*}{ Total } \\
\hline & \multicolumn{2}{|c|}{ Male } & \multicolumn{2}{|c|}{ Female } & \\
\hline & Observations & $\%$ & Observation & $\%$ & \\
\hline 1999 & 1058 & 76.50 & 325 & 23.5 & 1383 \\
\hline 2004 & 1057 & 78.30 & 293 & 21.7 & 1350 \\
\hline 2009 & 828 & 61.02 & 529 & 38.98 & 1357 \\
\hline
\end{tabular}

As shown in table 2, among the female headed households the poor female headed households accounted for $35.08 \%, 42.86 \%$ and $35.21 \%$ in 199 , 2004 and 2009 survey years respectively. On the other hand, poor male headed household's accounts for $35.63 \%, 39.24 \%$ and $35.34 \%$ of the male headed households 1999, 2004 and 2009 respectively. Over the survey periods it seems that poverty of female and male headed households is reduced. However the poverty incidence in the year 2004 is higher than the year 1999. The possible reason could be drought/shortage of rain fall that occurred in most part of the country during 2004. Only during this year (2004) the poverty of FHHs is greater than that of $\mathrm{MHHs}$. This is in line with the expectation that $\mathrm{FHHs}$ have less resilience to adverse conditions.

Table 2: Category of households in to poor and non poor based on household head sex.

\begin{tabular}{|c|c|c|c|c|c|c|c|c|c|c|}
\hline \multirow{2}{*}{$\begin{array}{c}\text { Poor/ } \\
\text { Non-poor (\%) }\end{array}$} & \multicolumn{3}{|c|}{1999} & \multicolumn{3}{|c|}{2004} & \multicolumn{3}{|c|}{2009} & \multirow{2}{*}{ t-value ${ }^{+}$} \\
\hline & $\mathbf{M}$ & $F$ & Total & $\mathbf{M}$ & $F$ & Total & $\mathbf{M}$ & $\mathbf{F}$ & Total & \\
\hline Poor & 35.63 & 35.08 & 35.5 & 39.24 & 42.86 & 36.46 & 35.34 & 35.21 & 35.275 & $2.95^{\star \star \star}$ \\
\hline Non poor & 64.37 & 64.92 & 64.5 & 60.76 & 57.14 & 63.54 & 64.66 & 64.79 & 64.725 & $4.32^{\star \star \star *}$ \\
\hline Total & 100 & 100 & 100 & 100 & 100 & 100 & 100 & 100 & 100 & \\
\hline
\end{tabular}

+ Test Statistics for the difference in poverty between MHHs and FHHs; ${ }^{* * *}$ and ${ }^{* \star *}$ significant at $1 \%, 5 \%$ and $10 \%$ respectively

Finding the factors that contribute to poverty goes beyond the descriptive analysis and requires employing econometric analysis. Multivariate econometric analysis helps us to identify factors influencing the extent of poverty. As it was discussed in the methodology part of the study, a Logit model is estimated to identify the major determinants of poverty of female headed households. The variables described in the descriptive analysis are used as explanatory variables in Logit model. Using the female headed household poverty as a dependent variable whereby a value of 1 is given to female headed households being poor and 0 otherwise, and using the identified explanatory variables, the model was estimated by following the maximum Likelihood estimation procedure. The measurement of goodness of-fit of the model shows that the model fit the data well. The Logit model helps us to identify the determinants that explain the probability that a female headed household is poor. Therefore, based on absolute total poverty line, we look through factors that determine the female headed household to fall below this poverty line. This section presents and interprets the estimation result.

Table 3: logistic estimation for determinants of poverty

\begin{tabular}{ccccccc}
\hline $\begin{array}{c}\text { FHHs Probability } \\
\text { to be poor }\end{array}$ & \multicolumn{2}{c}{$\mathbf{1 9 9 9}$} & \multicolumn{2}{c}{$\mathbf{2 0 0 4}$} & \multicolumn{2}{c}{$\mathbf{2 0 0 9}$} \\
\cline { 2 - 7 } & Coefficient & t value & Coefficient & t value & Coefficient & t value \\
\hline HHAGEF & 0.0066749 & 0.19 & -0.040141 & -0.53 & 0.005746 & 0.34 \\
HHAGE2F & -0.000142 & $-2.33^{*}$ & -0.000521 & -0.73 & -0.00016 & -0.75 \\
HHSIZEF & 1.134025 & $2.80^{*}$ & -0.182488 & $-5.56^{* * *}$ & -0.33189 & $-2.59^{*}$ \\
HHSIZE2F & -0.063679 & $-2.23^{*}$ & 0.0115154 & 0.54 & 0.012319 & 1.13 \\
LANDF & -0.654647 & $-4.28^{* * *}$ & -0.268666 & $-3.11{ }^{* *}$ & -0.0763 & -0.49 \\
TLUF & -0.075691 & $-3.48^{* *}$ & -0.164025 & $-2.49^{*}$ & 0.125777 & $3.87^{* *}$ \\
OXENF & -0.502817 & $-2.06^{*}$ & -0.30914 & -1.29 & -0.22229 & -1.69 \\
ILITERATEFD2 & 0.0510182 & 0.45 & 0.1351479 & 0.81 & 0.592859 & $2.29^{*}$ \\
CONSTANT & -3.75414 & -2.75 & 1.778249 & 0.76 & 1.380015 & 2.78 \\
\hline
\end{tabular}

* Significant at the $1 \%$ level; ${ }^{* \star}$ Significant at the $5 \%$ level; ${ }^{* *}$ Significant at the $10 \%$ level, Log pseudolikelihood $=-1246.2108$ Number of obs $=1357$, Wald $\mathrm{chi}^{2}(23)=412.5$, Prob $>\mathrm{chi}^{2}=0.0000$, Pseudo R2 $=0.2013$ 


\section{Alemi Negassa and Dereje Fekadu CONCLUSIONS}

This study has sought to assess the extent of poverty for female headed households in rural Ethiopia. In addition some of the key determinants of poverty are identified. Descriptive analyses, poverty measurement using FGT poverty indices and multivariate analysis have been employed for the study. The descriptive analysis of the data set indicates that on average $35.3 \%$ of the sample female headed households in rural Ethiopia are poor. Particularly, $35.34 \%$ of female headed households are poor in 2009. The proportion of illiterate $\mathrm{FHHs}$ is higher than that of MHHs Poor female headed households mainly achieved lower average grade level, lower mean values of household size, adult equivalent household size, less land holding and livestock ownership than non poor female headed households.

The estimation of the Logit model for determinants of poverty shows that larger household sizes significantly increase the probability of the FHHs to be poor. Similarly the probability of being poor is on average higher for female headed households relative to the male headed households. On the other hand, literacy of household head, livestock ownership and land holding have negative effect on poverty. In general, households with large family size and illiterate head, less livestock owned and land holding are more likely to be poor than other household heads.

So to address the issue of illiteracy investment in human capital has paramount significance in poverty alleviation in rural Ethiopia. Particular emphasis also should be given to adult education since majority of the adults are illiterate households with larger family size, less livestock owned and land holding are more likely to be poor than other household heads. Accordingly, current government policy to increase lands and labor productivity and increasing awareness among rural women in using family planning to reduce fertility should be encouraged.

\section{REFERENCES}

Bilisuma B. Dito. (2010). Intra Household Labor Supply, Agricultural Shocks and Women's Bargaining Power in
Sci. Technol. Arts Res. J., Jan-March 2014, 3(1): 152-155

Rural Ethiopia Paper to be presented at DIAL Development Conference, Shocks in Developing Countries, June $30^{\text {th }}$ and July $1^{\text {st }}$ 2011, Paris, Pp. 28-31.

Central Statistical Authority, (CSA), (2011). Report on the 1999/2000 Household Income, Consumption and Consumption Survey. Statistical Bulletin 258, Addis Ababa. Pp 9-15.

Federal Democratic Republic of Ethiopia, Ethiopia's Progress Towards Eradicating Poverty: An Interim Report on Poverty Analysis Study (2010/11).

Foster, J.E., Greer, J. and Thorbacke, E., (1984). A Class of decomposable poverty measures. Econometrica 52(3): 761-766

Fredu N. (2008). Rural poverty dynamics and impact of intervention programs upon chronic and transitory poverty in northern Ethiopiaa A paper selected for presentation at African Economic Conference 12-14 November 2008 Tunis, Tunisia, Pp.17-20

Gujarati, D., (1995), Basic Econometrics, McGraw-Hill International Editions, (3 ${ }^{\text {rd }}$ Edition). Pp. 305-307.

Hazel M. (2010). Poverty Among Women in Sub-Saharan Africa: A Review of Selected Issues, Pp. 12-15.

Khalid U. and Akhtar S. (2011) Poverty Dynamics of Femaleheaded Households in Pakistan: Evidence from PIHS 2000-01 and PSLM 2004-05.

Meron, A. (2009). Female-Headed Households and Poverty In Urban Ethiopia June 2009 Addis, Ababa University School of Graduate Studies, Pp. 15-17.

Ministry of Finance and Economic Development (MOFED) Dynamics of Growth and Poverty in Ethiopia (1995/962004/05 Development Planning an Research Department (DPRD) April, 2012 Addis Ababa Ethiopia, Pp. 121-127.

United Nations Development Program (UNDP), (2012). Human development Report 2002: Deepening Democracy in fragmented World, Oxford University Press, New York, Pp. 225-227.

Women's Affairs Office, Federal Democratic Republic of Ethiopia (WAO) and World Bank (WB), (1998). Implementing the Ethiopian National Policy for Women, Institutional and Regulatory Issue. Pp. 18-19. 